Article

\title{
Wind Technology: A Framework for the Evaluation of Innovations' Impacts on the Diffusion Potential
}

\section{Valentina Dinica}

School of Government, Victoria University of Wellington, P.O. Box 600, Wellington 6140, New Zealand; E-Mail: Valentina.Dinica@vuw.ac.nz; Tel: +64-4-463-5711; Fax: +64-4-463-5454.

Received: 21 December 2009; in revised form: 20 January 2010 / Accepted: 20 February 2010 / Published: 15 March 2010

\begin{abstract}
This paper proposes a framework based on which innovations in wind power technologies can be evaluated from the standpoint of their contribution to diffusion expansion. The framework helps build up a missing link between the technical literature on innovations and policy-oriented contributions concerned with the diffusion potential of wind power in national energy systems. The ideas are applied for the evaluation of wind technology innovations adopted in Spain. The framework can help policy-makers prioritize their innovation objectives and funding, so as to support the adoption of innovations that deserve the highest priority, given the country's resources and energy system characteristics.
\end{abstract}

Keywords: wind power; diffusion potential; technological innovations

\section{Introduction}

Increasing evidence of climate change seems to have finally convinced political actors in some countries that 'healing the wounds' of climate change impacts may be more expensive than implementing measures and adopting technologies that cut greenhouse gas emissions. Electricity production based on fossil fuels is a key contributor to climate change. Replacing fossil fuels with renewable forms of energy resources must be at the core of any genuine climate change mitigation strategy. The market adoption of renewable electricity technologies (RET) requires policy support on many fronts.

The institutional framework needs to be streamlined, to deal with social and administrative obstacles of subjective and bureaucratic nature. The confidence of economic and financing agents has 
to be won, based on governmental price support instruments that enable some minimum profitability levels at low political risks. But first of all, the innovation efforts of private companies willing to develop and deliver clean energy technologies should be supported by instruments such as research, development and demonstration (RD\&D) subsidies, third-party governmental financing of innovative technological designs (that do not enjoy the confidence of banks and insurance companies yet), and public-private innovation partnerships with governmentally funded research centers.

However, an analysis of numerous governmental policies aiming to stimulate RET innovations and their market adoption reveals two striking things. First, the technological innovation priorities stimulated are often not very helpful in expanding the diffusion potential of RET, in competition with the incumbent fossil fuel technologies. Governmental innovation policies rarely take into account the quality, availability, particularities and distribution of the renewable energy resources before innovation priorities are ranked. This poses the risk of mismatches between the types of innovations encouraged and the feature of the renewable energy resource the respective RET has to harness.

Second, the technical indicators used, in order to monitor and report on RET innovations, are often inadequate for understanding the real added value of the respective innovation: to what extent will it improve the potential of that RET towards a more significant share in the national energy system? For example, innovations in wind power technologies are typically monitored by means of the 'turbine installed capacity' indicator: a 3 MW design would be an innovation, in the context that no model of this installed capacity was manufactured before. But does this mean that the competitive position of wind power technology in relation to fossil fuel technologies has improved, as a result of this upscaling? Assuming that there is investment interest in this larger turbine design, does this mean that the ceiling of wind power contribution to the national energy system can be lifted by this innovation? Does this 'innovative design' to help remove any known obstacle for wind power diffusion? Market analysts and policy academics report on wind power innovations in similar, unsatisfactory, ways.

Besides, the academic literature on renewable energy is characterized by a poor connection between research on the preconditions for RET diffusion, on the one hand, and analyses of innovative RET types and designs, on the other. Studies concerned with the factors influencing the diffusion processes seldom look at the role and types of innovations benefiting the respective RET in the analyzed period. For example, Jacobsson and Johnson [1] developed an analytical framework for the study of RET diffusion and proposed to consider the influences on diffusion of factors such as: the network of actors involved in diffusion, the institutions involved in the approval and investment process, as well as the perceptions, competencies and strategies of firms involved in $\mathrm{R} \& \mathrm{D}$ and diffusion. Meijer et al. [2] explore how technological, political and resource uncertainties influence the motivations and decisions of entrepreneurs on whether to get involved in RET innovations and adoption or not. They argue that by reducing these uncertainties through good policies, policy makers may improve the diffusion prospects for RETs.

Increasingly more studies have revealed the implementation and institutional obstacles for RET, especially wind power, and formulated insightful policy recommendations on how to address them in various institutional settings [3-5]. The social acceptance of RET has been an important obstacle for many types of RET in many countries. Reflecting on experiences so far, Wustenhagen et al. [6] proposed a way to better understand social acceptance and influence it, by differentiating among three dimensions of acceptance: socio-political, community and market acceptance. Others, like Jacobsson 
and Lauber [7], focused on success stories for wind power and solar cell diffusion in Germany, reflecting on some policy and political success factors with potential for emulation. The list of diffusion oriented academic studies that have generated useful insights into diffusion obstacles, processes, mechanisms and preconditions for success is much longer than this paper can cover, given size limitations. However, such contributions, which can be referred to as 'diffusion studies', have not attempted to conceptualize or to operationalize (more importantly) the concept of RET innovations from a diffusion perspective. Currently there is a research gap in this area that needs to be addressed for a better integration of the diffusion literature and the innovation literature on RET.

A good look at the studies looking at RET innovations shows that not much progress has come from this direction either. In this stream of 'innovation studies', two sub-streams of interest need to be differentiated. First, there are professional/industry and technical/engineering academic studies discussing the technical innovations brought about to RET, published typically in professional or industry association journals and newsletters, or RET focused national or international journals such as Windpower Monthly, Re-focus, and Renewable Energy World, or technical academic journals such as Wind Engineering; but such studies also appear in book forms [8-10]. Their importance in shaping stakeholders' perceptions regarding RET innovations should not be underestimated as they are quite widely read by RET analysts, junior and senior academic staff and industry professionals.

Most such studies reporting on RET innovations are self-absorbed in quite dry descriptions and details on the novel models (see for example [8-10]). This type of 'technical innovation studies' are rarely concerned with the consequences of RET innovations for the extent and prospects of diffusion. While the focus is on description of 'new' designs and models of RET, such contributions typically stop short of reflecting on the importance of the novel aspects discussed for the diffusion prospects of the respective technology. The study of Hansen et al. [11] is one of the very few, identified by the author of this paper, that looks at the market penetration of certain wind turbine innovations. They have chosen to analyze the diffusion of wind turbine designs that have innovative features on two very important technical aspects: power control ability and speed control ability. They carry out a quantitative global diffusion overview of the innovative designs produced by the top 10 manufacturers of wind technology in the world between 1998 and 2002. However, their study is at global level. They do not report any data at national level, nor do they consider the issues of (mis)match between the selected innovative turbine features, on the one hand, and important national level factors such as the wind energy resource characteristics and grid characteristics, on the other hand. Their analysis is global, while contextual national-level diffusion analyses are better capable of improving the understanding of the usefulness of innovations from a diffusion perspective. This paper will argue that the 'usefulness' of innovations is in most cases context dependent, and a national level perspective of analysis is crucial.

The second stream of relevant studies can be referred to as 'social science innovation studies'. This is a very wide stream of literature and not all contributions are relevant for-or, indeed, interested in - understanding the direct implications of RET innovations for the diffusion prospects of that technology. Many innovation studies have different goals than contributing to the understanding of RET diffusion. For example, Kamp et al. [12] are interested in various ways of learning to innovate in wind power technology. They are mainly concerned with the impacts of diffusion (among others) on innovation, not with the consequences of innovations for diffusion, which is at the heart of this paper. 
Numerous innovation studies take a macro level analytical perspective looking at how politics, institutions, policies, infrastructural settings and social contexts affect progress and directions in RET innovations [13,14]; but, again, the consequences of innovation features for diffusion prospects are outside the scope of their interest. The list of innovation studies not taking this approach is too long to include in the literature review for a journal-size paper. More important is that the author has identified very few articles where academics are interested in the diffusion consequences of innovations.

Good examples_-from this very small sample_-would be the work of Uyterlinde et al. [15] and Neij [16] who are explicitly and directly concerned with the impact of technological developments on the prospects of RET diffusion in Europe. A major limitation, however, is that the authors restrict their studies to the issue of cost reductions associated with the assumed, expected technological developments in RETs. Another limitation is that their quantitative model is not differentiated and operationalized per type of RET, and does not consider at all the technical features of RET innovations and how these fit into the national resource structure of the respective renewable energy type, or into the grid infrastructure. These aspects need to be considered as well, for a comprehensive picture of how innovations can affect diffusion prospects.

At this stage, the research interests of both innovation-oriented and diffusion-oriented analysts have left uncovered a considerable research gap: how do the technical features of RET innovations help improve the diffusion prospects and lift the diffusion potentials for RET? This paper aims to contribute towards bridging this gap. It does so by bringing to the attention the under-researched aspect of sustainability (continuity) of the market diffusion processes. It is argued that a meaningful way of looking at innovations is one that considers the diffusion expansion potential that innovations in the respective technology bring about.

The sustainability of market diffusion is a process that regards the increase in installed capacity (or electricity production) based on a certain renewable energy resource, up to the maximum usable potential, or until the grid integration ceiling has been reached, whichever is higher. Innovations with diffusion expansion potential are those that:

- reduce diffusion obstacles (before the usable resource potential is exhausted); and/or

- lift the previously known and applied ceilings of: a) usable resource potential and/or b) grid integration ceiling (this is further elaborated in Section 5).

Diffusion sustainability also refers to the re-powering of the capacity already commissioned, when innovations are unable to lift the diffusion ceiling(s) any further.

Typically, diffusion studies look at the impacts of various independent and contextual variables on either the installed capacity operating in a country/region at a certain moment in time, or on the share of RET in energy/electricity production. Therefore, the dependent variable is merely a 'snapshot in time', which says little about the chances for that technology to become a permanent presence in the energy production landscape of the respective country. If we are to more towards a society with sustainable production patterns, we have to make sure that the contribution of RETs to national energy systems is maximized and sustained in time.

This paper proposes a general analytical framework for the evaluation of the contribution of technical innovations to the sustained diffusion of RET in national energy systems. The general framework, exposed in Section 3, is operationalized for the case of wind power technology. The 
framework was operationalized elsewhere also for the cases of biomass electricity technologies and small hydropower [17]. Due to space restrictions, this paper refers only to onshore wind power. Section 4 discusses the diffusion obstacles encountered by onshore wind technologies. The operationalization of the evaluation framework for the case of wind power results in the specification of a set of four general indicators of technological performance. The paper proposes that innovations be evaluated by means of these indicators, in order to underpin their consequences for the national diffusion potential.

In the case of wind power, the relationship between the wind energy potential and the ceiling of wind power contribution to national electricity consumption has consequences for the most desirable innovations in wind technology in the respective country. Innovation priorities may differ as well for the short-medium term and for the long term. If adopted according to such ideal, 'technical priorities', innovations may actually even lift the initially estimated contribution of wind power to electricity consumption. These issues are explored in Section 5. Following this, Section 6 elaborates further on a set of technical indicators for the evaluation of wind power innovations from the (more complex) perspective of grid friendliness and compatibility with stand-alone applications. Section 7 illustrates the usefulness of this evaluation framework by means of analyses on the innovative wind technology designs adopted in Spain. Section 8 offers some concluding reflections.

\section{A Critical Eye on the Use of Technical Indicators for Wind Power Innovations in the Literature}

Wind power technology emerged more than four decades ago [18]. Numerous technological designs were developed and tested, which improved technical and cost performances [19]. However, technical studies reporting on progress have been traditionally very un-transparent to policy makers and market analysts in terms of what do innovations mean for the market diffusion prospects and potential. More importantly, policy makers and market analysts have typically been unaware of this lack of transparency. This is because it was assumed that all innovations result in increased market diffusion potential. As this study argues, this is not always the case.

Besides, policy makers and market analysts have been predominantly preoccupied with only few aspects of innovations that could be easily understood without much technical background. In the case of wind power, these have been: the level of installed capacity of individual turbines, rotor diameter and hub height. In this case, the assumption has been: the bigger, the higher the market diffusion potential [20]. This paper argues that, while such indicators play important roles, they are not sufficient for understanding the innovations' impacts on the diffusion potential of wind technology. Higher installed capacity per turbine does not always mean that turbines are more efficient in terms of wind energy harnessing. The energy resource and grid characteristics are important factors in determining if, and to what extent, a technical innovation is useful from a diffusion perspective.

So far the emphasis of manufacturers (and the research and development policy objectives of governments) was to produce wind turbines with ever-higher installed capacity [20,21]. Towards the end of the 1990s, increasingly more manufacturers started to produce wind turbines in the range of 1-3 MW. In 2001, turbines of $5 \mathrm{MW}$ were being tested, while currently wind turbines of $10 \mathrm{MW}$ are not uncommon. However, at a certain moment this up-scaling will reach a ceiling. Engineers explain 
that the main constraining factors will be the 'actual engineering of turbines and the ability of using and handling them. (...) Turbine blades may be the factor that puts a physical limit on the size of turbines. Rotor sizes of around 150 meters - suitable for turbines of about $5 \mathrm{MW}$ - are generally thought to be the largest that could function (...) due to their weight' [20].

The question Jones [20] asks is: 'Are bigger turbines more efficient?' Theoretically speaking-in terms of efficiency of wind energy harnessing at a certain site - the answer is 'yes', because the energy harnessed increases with the cube of the wind speed. At higher hub heights, wind speed will be higher, and the respective wind turbine will harness wind energy more efficiently at that site. However, the next question that emerges is: Are all innovations that focus on size also beneficial from the perspective of maximizing the contribution of wind power to national energy systems? In this case the answer is 'not always', because the turbine needs to be suitable for the annual average wind speed of the site. If wind speeds are moderate or low for a considerable range of heights, it does not help to install large capacity turbines, because they will probably not reach the nominal power for which they were designed, and they will always function at inferior capacity.

Therefore, I support the argument of some leading wind power experts that turbine capacity is not a very useful indicator of technological performance and innovation, because, if high wind speed resources are missing in the respective country, the use of larger turbines does not lead to higher rates of wind energy harnessing [11,18,20,21]. For similar reasons, blade size and hub height are also not very useful indicators, from the perspective of consequences for diffusion potential $[11,18,20,21]$.

\section{A Framework for the Evaluation of Innovations in Renewable Electricity Technologies}

This section proposes to differentiate between three levels of classifying technologies and innovations for electricity generation based on renewable resources: technological approaches, principles and designs, as suggested in Figure 1. Electricity can be generated based on different technological approaches, which define the forms of energy underlying electricity generation and the chain of energy transformation processes leading to it. The most conventional technological approach assumes the transformation of the chemical energy embedded in fossil fuel resources into thermal energy, and further into mechanical energy and electric energy. Another technological approach assumes the direct transformation of solar energy into chemical energy and afterwards into electrical energy. A different technological approach assumes the use of kinetic energy of air masses (wind energy) and its transformation into mechanical energy and finally into electrical energy.

Figure 1. A performance based perspective on technologies and innovations.

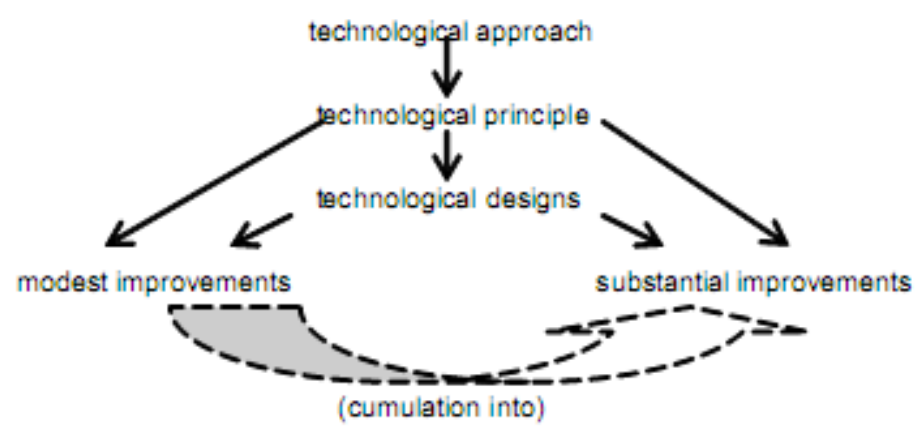


Each technological approach for electricity generation can rely on more technological principles that differ fundamentally on the technical aspects of transforming one form of energy into another. Therefore, a technological principle refers not to the forms of energy that undergo conversion, but to the transformation processes that take place. In the renewables' domain, biomass energy can be transformed into electrical energy either through direct burning or by means of biomass transformation into a combustible gas (the gasification principle) or by means of biomass conversion into an oil that can be used also in combustion for electricity generation at higher efficiency (the pyrolysis principle). Likewise, wind energy can be transformed into mechanical energy either based on the vertical axis turbine principle or based on the horizontal axis turbine principle.

A technological principle can be developed into more models/types of design. For wind power, one can find different types of rotor speed designs and blade control designs, which can be combined either with asynchronous or with synchronous generators (see Section 6). Technological designs assume technical variations that, while being based on the same technological principle, may result in different performances such as efficiency of renewable resource harnessing, or environmental impacts, or use in stand-alone applications (not connected to grid infrastructures).

The literature on technological innovations typically differentiates between radical and incremental innovations. Often no definition is given as for the criteria used for categorizing various innovations as such. When definitions are provided, the perspective on innovativeness varies greatly. Garcia and Calantone [22] reviewed the use of terms such as radical, really new, incremental and discontinuous innovation in the new product development literature. Differentiating among 15 perspectives of defining innovation in a sample of only 21 studies they observe that 'innovativeness is most frequently used as a measure of the degree of newness of an innovation. However, little continuity exists (...) regarding from whose perspective this degree of newness is viewed and what is new'. As many as 23 perspectives on newness have been differentiated, for example 'new to the world', 'new technology features', 'new uses' and so on.

In this paper, 'innovation' does not mean 'latest model'; it is not concerned with the degree of novelty of the 'new technological designs' or technical principles incorporated in RET. The main focus is on what innovations can contribute towards an increased market share of the respective RET and a long-term continuity of diffusion processes. This is because the main interest here is on the extent to which innovations, through the improvements brought about, can contribute to the removal of obstacles facing RET diffusion, enabling a higher contribution of that RET to national energy systems.

Not all improvements are directly relevant or crucial for overcoming the barriers faced by a RET. Some innovative characteristics could bring about substantial changes in the performances of a technology, affecting the extent to which market diffusion can be successfully sustained in the long term. Others will make only small steps in that direction, while still others may bring about changes in previous models without any meaningful performance improvements.

I differentiate between innovations with 'substantial' and 'modest' performance improvements from the perspective of their diffusion expansion potential. I define as technological design/principle with substantial performance improvements those innovations characterized by performances that eliminate or reduce substantially one or more diffusion obstacles, faced by the incumbent designs of the technology. Such obstacles may be of technical, social/administrative, or economic nature. Further, I define as technological design with modest performance improvements those innovations 
characterized by performances which, although reduce or eliminate certain small drawbacks of incumbent designs, do not contribute to the removal of diffusion obstacles, nor do they contribute to substantially improve the prospects for a larger market share of that RET, in long term.

The possibility exists, however, that innovations in a certain design, although bringing about just modest performance improvements, cumulate in time and have synergy effects leading to the removal of one or more obstacles that impede a substantial and sustained market diffusion. These ideas are represented in Figure 1 and they will be operationalized for wind power in Sections 4, 5 and 6. Finally, I consider as conventional both the old and the new technological designs that are performance-neutral from the perspective just mentioned. Although conventional designs also contribute to market share increase, if all investments are made only with conventional design, the maximum feasible diffusion potential will be lower as compared to the case when better performing designs are adopted, able to exploit the respective renewable resource at a higher efficiency rate, at much more locations, and with a high power output quality.

\section{An Operationalized Framework for the Evaluation of Wind Power Innovations}

This section operationalizes the evaluation framework proposed in Section 3 for the case of onshore wind technology. First, it reviews the diffusion obstacles with possible solutions in the technical domain that are still facing the large-scale adoption of wind technologies. Second, it specifies the performance-perspectives based on which the analysis of the diffusion potential of technological designs should be best made.

Electrical wind systems are based on a technological approach whereby electric power is generated by transferring the kinetic energy of the wind captured by blades into mechanical energy, which is used to move a turbine connected to an electrical generator [18]. Two technological principles emerged for the harnessing of wind energy: the vertical and horizontal axis principles. Vertical axis wind systems are most suitable for mechanical applications, such as windmills and windpumps, while horizontal axis technologies are more adequate for electricity generation [19]. A study of the European Commission Directorate for Energy observes that 'While judgement on many design options in wind turbine technology has been deferred, there is now an overwhelming vote in favour of horizontal axis technology' [21]. Consequently, the paper only discusses the technological designs that emerged based on the horizontal axis principle.

\section{Technical Obstacles of Wind Technology}

An overview of the technical literature reveals a series of technical obstacles that onshore wind technology has been facing. First, a more significant market diffusion of wind technology has been impeded by the micro and macro-fluctuations of wind power availability [11]. The variability of wind power availability leads to negative impacts on grid management due to voltage and frequency fluctuations of the electricity delivered [11,18]. In addition, when certain types of turbines are used, wind variability may even destabilize a weak grid. At the start-up of turbines, and when wind speeds are low, turbines need to consume electricity from the grid in order to maintain their rotor speed velocity. This is referred to as the need for 'reactive power' [23,24]. The unpredictability of 
wind power availability makes it difficult to use wind energy in stand-alone applications without back-up power.

'Reactive power' also forms an inconvenience for grid-connected applications, because when the generation of wind electricity cannot meet the level of demand, back-up power must be supplied at system level. Both the micro and macro-fluctuations pose constraints on the extent to which wind power can be integrated in grid systems and the extent to which they can be used in stand-alone applications [24]. Therefore any technological design that is able to make wind technology grid-friendly and compatible with stand-alone applications is referred to in this paper as 'diffusion-optimal'. The indicators for this type of technical performances are explained in Section 6.

Second, the low efficiency of wind energy harnessing and its conversion into electricity has long been an obstacle towards lifting the contribution of wind power in national energy systems. This has also a negative impact on the cost performances of wind technology, which is a second disadvantage [19]. In the first years of technology development, comparisons regarding the efficiency of wind energy harnessing among different types and sizes of turbines were made by using the indicator of 'capacity factor'. This expresses the ratio of the amount of electricity produced on an annual basis $(\mathrm{kWh})$ per unit on installed capacity $(\mathrm{kW})$. However, the capacity factor proved to be a poor indicator. The parameter of electricity produced per square meter of area swept by the rotor- $\mathrm{kWh} / \mathrm{m}^{2}$ - is currently the most preferred indicator of technical experts (e.g., [20,25-27,33]).

Progress in efficiency has been achieved by means of increases in the hub height of turbines, rotor diameter and the possibility of turbines to maintain their rated power at wind speeds above the nominal values. Some studies mention a doubling of efficiency in only 15 years, with increases from $600 \mathrm{kWh} / \mathrm{m}^{2} /$ year in 1985 to around $1,150 \mathrm{kWh} / \mathrm{m}^{2} /$ year in 2000 [23]. However, there are still important efficiency differences among the many types of designs currently on the market and efficiency is still seen as a remaining technical challenge for wind technology.

Further improvements in efficiency are still expected [23]. As the world-wide use of wind energy resources is often constrained by the availability of land, it is important that the available sites are exploited to the maximum levels possible [18]. Consequently, the contribution of innovations to the diffusion expansion potential needs to be also analyzed from the perspective of the increase in the annual electricity production per square meter of rotor swept area. But it would be arbitrary to trace a line for a level of $\mathrm{kWh} / \mathrm{m}^{2}$ efficiency above which technical progress should be considered as bringing substantial or only modest improvements to the diffusion expansion potential; the higher the value of this parameter, the better the prospects for market share increase and sustained diffusion.

Third, wind technology was criticized for not being able to extract energy at low wind speeds, $5 \mathrm{~m} / \mathrm{s}$ and below, dominating in most regions across the globe [18]. The aspect of wind speed is crucial for the extent to which wind energy can play an important role in the future energy systems, worldwide. As Menedez [28] explains 'A route for the extension of wind energy application is to advance the design of turbines which work in low wind speed regimes. In large regions of the world there are frequent winds but with average velocities below $5 \mathrm{~m} / \mathrm{s}$ and their harnessing could be an important source of electricity, although now this is contemplated as a remote alternative claiming higher costs than the actual technological designs'.

Most turbine models currently on the market are designed to function for wind speeds between $4 \mathrm{~m} / \mathrm{s}$ and $25 \mathrm{~m} / \mathrm{s}$ [20,23]. But they are able to reach their rated power only at nominal wind 
speeds for $11-16 \mathrm{~m} / \mathrm{s}$; this value can vary from manufacturer to manufacturer. Although technical progress has been achieved by several manufacturers, there is still a long way to go. Few companies developed turbine models able to reach rated power at nominal speeds in the range of $8-10 \mathrm{~m} / \mathrm{s}$ [28]. The ability of wind turbines to operate in moderate wind speeds can be described as bringing modest improvements to the diffusion expansion potential. However, given the worldwide dominance of average annual wind speeds of $5 \mathrm{~m} / \mathrm{s}$ [18], I will consider a design as 'diffusion-optimal' when it enables turbines to reach rated power at $5 \mathrm{~m} / \mathrm{s}$ or below.

The cost-competitiveness of RET is a precondition for sustainable diffusion processes. Hence, I propose a fourth perspective for evaluating the innovativeness of wind technology designs based on diffusion expansion potential: the extent to which an innovation contributes to cost-convergence with the incumbent electricity technologies. Cost-convergence, expressed as costs per MW, may occur both as result of a series of modest improvements that cumulate after some time, or as result of a single innovation. I consider that the technology-specific investment cost per MW constitutes a better indicator than that of cost per kilowatt-hour $(\mathrm{kWh})$ because production costs reflect many cost components - such as infrastructural costs, administrative/permit costs and others - that obscure the real cost performances achieved by technological innovations.

In this context, I consider that the evaluation of the diffusion expansion potential of wind technology innovations needs to be made from four performance-perspectives:

- the ability to close the cost-gap with conventional fossil-fuel based technologies, in terms of technology-specific costs per MW;

- the improvements in the efficiency of wind energy harnessing, in terms of $\mathrm{kWh} / \mathrm{m}^{2}$;

- the ability to function in average (below $8 \mathrm{~m} / \mathrm{s}$ ) and low wind speeds (below $5 \mathrm{~m} / \mathrm{s}$ ); and

- the contribution towards grid-friendliness and compatibility for stand-alone application.

\section{The Country-Specificity of Innovation Needs for the Sustained Diffusion of Wind Power}

As already pointed out in the introduction, the sustainability of market diffusion is a process that regards the increase in installed capacity (or electricity production) based on a certain renewable energy resource, up to the maximum usable potential, or until the grid integration ceiling has been reached, whichever is higher. Innovations with diffusion expansion potential are those that:

- $\quad$ reduce diffusion obstacles (before the usable resource potential is exhausted); and/or

- lift the previously known and applied ceilings of the: a) usable resource potential and/or b) grid integration ceiling.

From this perspective, two situations can be differentiated, with consequences for the types of technology designs needed with priority in a certain country. The two cases are represented in Figure 2. The first situation is when at a certain moment in time, the net exploitable wind energy potential at country level is lower than the technically feasible ceiling for grid integration of wind technology-Situation A in Figure 2. In this case, innovative designs should to be developed and adopted with priority, which are able to increase the level of exploitable resources. Diffusion will reach a ceiling, unless designs are developed that are able to harness the available wind energy 
potential substantially more efficiently and to lower the cut-in speed so as to exploit also areas with low wind speeds.

Figure 2. The sustainability of diffusion processes and requirements for wind technology.

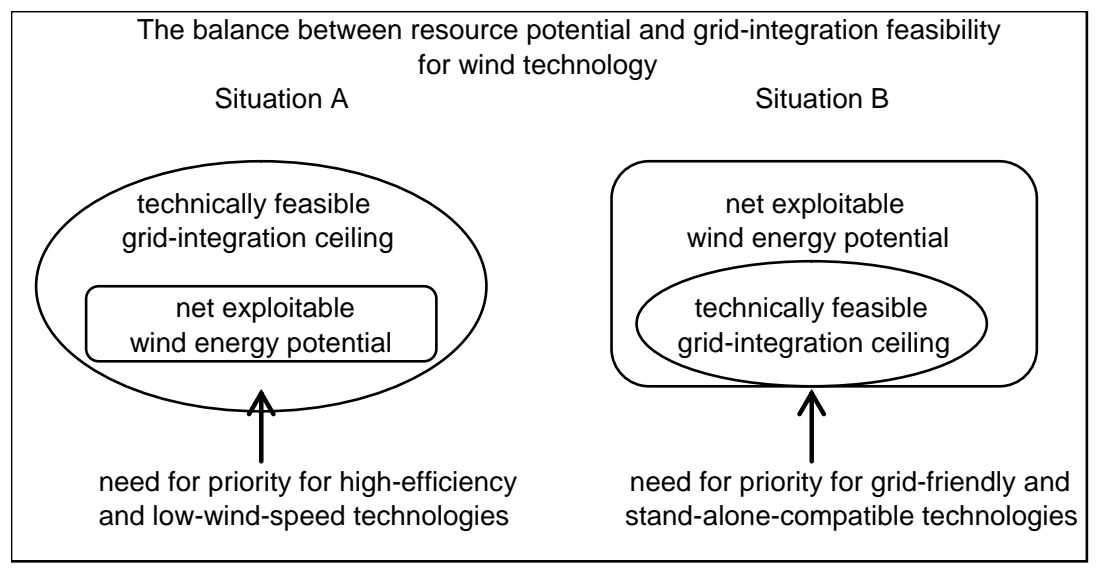

This scenario includes the assumptions that: (a) there is sufficient governmental price support for wind power production, to harness the technically available wind potential, or that other innovations (or legal changes for the incorporation of environmental impact costs) have already made wind electricity production costs competitive with conventional technologies; (b) there are no other diffusion obstacles of bureaucratic or emotional nature, such as social opposition, administrative procedures etc. If innovations are not able to lift the ceiling of wind energy harnessing, the sustainability of market diffusion processes becomes then, in Situation A, a case of market re-powering. If, in contrast, innovations are adopted that are able to harness wind power at lower wind speeds than the state-of-the art technology allows, and to do so substantially more efficiently (very high values for $\mathrm{kWh} / \mathrm{m}^{2}$ ), the diffusion potential of wind power in the national energy system will increase. Such innovations contribute to a sustained diffusion of wind power.

The second situation possible is when the technically feasible grid integration ceiling is/becomes lower than the net exploitable potential, as illustrated in Situation B, Figure 2. Some countries are very rich in wind energy resources such as United Kingdom. In this case, other types of innovations would be necessary to sustain the diffusion of wind power in the national energy system. These are the grid-friendly types of technologies able to supply high quality power-canceling the micro-fluctuations in voltage and frequency and with no need for reactive power (under the same two assumptions as above). The market adoption of such innovative designs would improve the prospects for market share increase of wind power through both grid-connected installations-lifting the technical ceiling for grid integration, and stand-alone applications (see Section 6). The overall potential contribution of wind energy to the respective energy system would be higher than in the case when such designs were not developed and adopted in the market.

The micro-fluctuations of electricity quality and the macro-fluctuations of wind power availability brought about warnings from grid managers. They argue that the degree of penetration of wind technology in the current electricity systems in the form of grid-connected installations is limited. Some suggest that the percentage of wind electricity that can flow through a national grid system depends also on the strength and characteristics of the grid itself [28]. In general, many argue that the 
smaller the grid, the lower the ceiling of grid penetration for wind energy is. The most serious problems are in island systems and stand-alone applications.

Some experts argue that the ceiling of grid-integration is country-specific also because it depends on the balance between flexible and inflexible generation technologies in the energy system of a country. Harnell and Landberg [24] explain that power plants have different levels of ability to respond to fast changes in electricity demand. Nuclear power plants for example are best operated at constant load due to safety reasons. Landfill-gas plants and power plants based on combined cycle gas turbines also have limited flexibility. Coal-based plants and open-cycle turbines based on gas or oil can be flexibly operated.

From the category of RET, hydropower plants with storage systems and plants based on energy crops of wastes' burning are able to be flexibly operated, while pumped-storage hydropower plants are actually the most flexible energy systems. Run-of-river small hydropower, wind systems and solar systems are inflexible intermittent systems. From this standpoint, the higher the market share of power plants using flexible technologies - based either on renewable or conventional resources, the higher the potential contribution of intermittent and unpredictable renewable resources such as wind can be.

\section{Indicators for the Diffusion Expansion Potential of Wind Technology Designs}

Section 4 already mentioned some indicators useful for the evaluation of wind technology innovations from the standpoint of diffusion expansion potential:

- turbine efficiency: $\mathrm{kWh} / \mathrm{m}^{2} / \mathrm{year}$

- ability to work in average/low wind speeds: turbines able to reach rated power at nominal speeds of $8 \mathrm{~m} / \mathrm{s}$ or even $5 \mathrm{~m} / \mathrm{s}$;

- cost competitiveness: costs per $\mathrm{kWh}$, as compared to competing (mainly fossil-fuel based) technologies.

This section refers to the forth perspective of innovation evaluation, looking at the most suitable technical indicators for grid-friendliness and compatibility to stand-alone applications. Based on a wide overview of technical literature, I consider that three technology characteristics are directly relevant for innovation evaluation in terms of progress to reduce the negative consequences of micro- and macro-fluctuations: the type of voltage regulation, the type of rotor speed, and the type of generator. The voltage of the electricity supplied by a wind turbine can be regulated by means of two systems: pitch control and stall control $[11,18,19]$. In pitch regulation the angle at which blades are positioned relative to the area described by the rotor's blades in their circular movement can be adjusted, either collectively or individually. But in a stall control system the angle is fixed during manufacturing.

The difference in performance is very important as pitch control turbines are able to keep the voltage level stable when wind speed increases above the nominal level for which turbines are designed. In contrast, stall-controlled turbines experience reductions of voltage levels as wind speeds increase above the nominal speed, meaning that turbines will function below the nominal installed capacity for which they were designed [11,25]. Under this design, "power is regulated by the 
progressive loss of rotor efficiency' [21], and the voltage control system is also referred to as 'control through aerodynamic losses' [23].

The higher the ability of wind turbines to stabilize voltage, the higher the penetration of wind technologies in current grid electricity systems can be, given the same wind resource quality and potential. In addition to this advantage, pitch regulated machines are also able to generate more electricity in terms of kilowatts per square meter of rotor area [26], since the voltage at which turbines generate power at winds above the nominal level does not decrease as in the case of stall regulated turbines. The European Commission mentions 'Concern about power quality of stall regulated machines (also especially in the German market) has deterred some manufacturers, who supply medium size stall regulated machines, from continuing this design feature in their megawatt designs' [21].

The second technical characteristic relevant for the expansion of the diffusion potential is the type of rotor speed. There are three technological designs on the market: constant speed rotor, variable speed rotor and two-speed rotor. Technical literature indicates that the most advantageous are the variable-speed rotors and two-speed rotors because they are able to deliver power voltage of higher quality, higher levels of electricity production, and to extract wind energy at lower wind speeds $[11,21,26,28]$. For variable-speed turbines, in order to maximize the benefits mentioned, a large range of variable speed is necessary, around a factor of 2.5 to 3. As a technical study for the European Community explains [21] 'Wind turbines result in fluctuations in real and reactive power, and hence in voltage level. Voltage fluctuations can cause consumer annoyance through the phenomenon of flicker where the light intensity from incandescent lighting fluctuates perceptibly. Variable-speed wind turbines generally produce significantly lower flicker than fixed-speed machines. Flicker can be an important issue for weak networks. Flickers and harmonics, and other related issues, come under the heading of power quality'.

In terms of efficiency improvements, recent studies comparing the electricity output from three wind turbine designs reveal that 'two-speed machines produce $6.4 \%$ more energy per unit swept area at a wind speed of $6 \mathrm{~m} / \mathrm{s}$ than a variable speed machine with similar ratings. At $10 \mathrm{~m} / \mathrm{s}$ the two speed turbine produces only $1.6 \%$ more' [25]. However, the variable speed machine produces $10.5 \%$ more energy at $6 \mathrm{~m} / \mathrm{s}$ site, down to $5.2 \%$ at $10 \mathrm{~m} / \mathrm{s}$ than a constant speed turbine. Therefore, at low wind speeds, the two-speed turbines have the best performances in terms of the capacity to harness wind energy $\left(\mathrm{kWh} / \mathrm{m}^{2}\right)$, followed by variable-speed turbines. At higher wind speeds the differences in efficiency performance are smaller.

The third technical characteristic relevant for the prospects of integration of wind technology in national electricity systems is the type of generator used in turbines. Two types are possible: asynchronous and synchronous generators $[18,23,26]$. Asynchronous generators have the disadvantage that they need to consume electricity, especially at start and during low speed winds of low intensity [27,28]. For grid-connected installations this reactive energy comes from the grid itself and creates negative synergies with the impacts on grid management attracted by the intermittent and unpredictable nature of wind availability. But, still, asynchronous generators are a feasible option for grid-connected application. Some manufacturers are even supplying their turbines together with compensation units, such as condensers, in order to minimize the effects of reactive energy demand [26]. However, when asynchronous turbines are used for stand-alone applications, it is 
necessary to accompany the wind installation by a special system that is able to generate electricity for the reactive demand of turbines. This can be a diesel motor, an energy storage system or an accumulator, for example, but the economic disadvantage is that it can represent $30 \%$ of the total investment costs of a stand-alone wind-based electricity installation [23].

The best option for stand-alone applications is to use synchronous generators. In 1992, the German company Enercon launched its $500 \mathrm{~kW}$ E-40 synchronous model, which was also the first design to combine the variable rotor speed concept with the synchronous generator option, giving the company a strong international position. Synchronous turbines are also better options for grid-connected applications than asynchronous turbines because, by avoiding the uptake of reactive energy from grid that causes voltage and frequency fluctuations, they avoid the disturbance of grid management $[20,23,26]$. This way they are also able to lift the ceiling for the grid-integration of wind technology that grid managers are so frequently warning about.

The general director of the Spanish manufacturer Made argues, 'Only the synchronous turbines are authentic generators, as a conventional power plant can be. (...) We believe that they are better options for the future because when the capacity of installed wind power increases considerably, distribution companies could place restrictions on the turbines that are not synchronous' [26]. Consequently, given the superior technical performances of synchronous generators, which make them the best choice both for grid-connected application and for stand-alone systems, I consider that this innovative feature brings about substantial improvements in the diffusion expansion potential of wind technology.

Having in view the current technical barriers threatening the continuity of market diffusion processes for onshore wind technology, I consider as innovative with substantial performance improvements those models/designs that have the following technical characteristics:

- $\quad$ synchronous type of generator; and

- $\quad$ variable speed rotor, or two-speed rotor; and

- pitch control type of voltage regulation.

When innovative designs only have the last two features they can be viewed as bringing only 'modest performance improvements' for wind technology. The improvements are 'modest' because they are not able to provide the same levels of power quality and efficiency of wind resources' harnessing as the designs with synchronous generators; but still they perform better on these aspects than the conventional designs (characterized by: asynchronous generators, constant rotor speed and stall control of voltage).

In spite of higher investment costs, designs with the latter two features are able to yield more electricity per plant life-time, compensating for the higher initial costs and bring more profits [24]. Being attractive for investors, they may increase the extend of market adoption, contributing this way to the long-term diffusion potential. However, if these designs are not endowed with special devices in order to deal with the negative aspect of asynchronous generators, namely the demand for reactive energy, they are not sufficiently grid-friendly nor are they compatible for use in stand-alone applications.

In conclusion, the characterization of a technological design from the perspective of diffusion expansion potential needs to take into account to what extend the design overcomes the incumbent technical obstacles and/or enables the achievement of a higher market share in long-term. I consider 
that technical innovations are able to expand the diffusion potential of wind power in national energy systems when they bring about improvements in one or more of the following performance aspects:

(1) grid-friendliness and compatibility with stand-alone applications; currently the best performing designs incorporate all of the following innovations introduced during (mostly) the 1980s and 1990s: pitch control of voltage regulation, variable speed rotor and synchronous generators;

(2) high efficiency rates of transforming wind energy resources in electricity;

(3) ability to function in low and average wind speeds (below average annual levels of $5 \mathrm{~m} / \mathrm{s}$, respectively $8 \mathrm{~m} / \mathrm{s}$ ); and/or

(4) cost-competitiveness with competing fossil fuels based electricity technologies.

Consequently, I operationalize the term 'substantial and/or modest contribution to sustained diffusion', by means of the indicators mentioned on dark background in Table 1. The remaining part of the paper applies these ideas on the evaluation of innovative technological designs adopted in Spain. The empirical data based on which the analyses in Sections 7 are made were collected by the author between 2000 and 2001, in the framework of a four year doctoral project [17]. Similar analyses were carried out for United Kingdom and The Netherlands. Due to space restrictions, I chose to present the Spanish case, as wind power diffusion was more substantial, with 2,900 MW installed by 2000.

Table 1. Diffusion obstacles and indicators for wind technology innovations addressing them.

\begin{tabular}{|c|c|c|c|}
\hline $\begin{array}{l}\text { Obstacles to } \\
\text { diffusion } \\
\text { expansion }\end{array}$ & $\begin{array}{c}\text { Performance } \\
\text { improvements } \\
\text { brought about by } \\
\text { innovations } \\
\end{array}$ & $\begin{array}{l}\text { Technical indicators } \\
\text { of innovations }\end{array}$ & $\begin{array}{c}\text { Potential contribution to lift diffusion } \\
\text { obstacles and ceilings }\end{array}$ \\
\hline \multirow{2}{*}{$\begin{array}{l}\text { 1. micro and } \\
\text { macro voltage } \\
\text { fluctuations }\end{array}$} & \multirow{2}{*}{$\begin{array}{l}\text { grid-friendly and } \\
\text { stand-alone } \\
\text { compatible }\end{array}$} & synchronous generators & substantial \\
\hline & & $\begin{array}{l}\text { pitch control of blades; } \\
\text { variable/two rotor speed }\end{array}$ & modest \\
\hline \multirow[t]{2}{*}{$\begin{array}{l}\text { 2. low efficiency } \\
\text { in wind use at } \\
\text { given sites }\end{array}$} & \multirow[t]{2}{*}{$\begin{array}{l}\text { increased efficiency } \\
\qquad\left(\mathrm{kWh} / \mathrm{m}^{2}\right)\end{array}$} & $\begin{array}{c}\text { improved technical } \\
\text { processes or materials; } \\
\text { larger rotor area }\end{array}$ & $\begin{array}{l}\text { modest } \\
\text { (substantial improvements achieved by the } \\
\text { end of 1990s through gradual small steps; } \\
\text { improvements still possible) }\end{array}$ \\
\hline & & $\begin{array}{l}\text { pitch control of blades; } \\
\text { variable / two rotor speed }\end{array}$ & modest \\
\hline $\begin{array}{l}\text { 3. cost / } \mathrm{kWh} \\
\text { performances }\end{array}$ & $\begin{array}{l}\text { reduction technology } \\
\text { specific costs }\end{array}$ & $\begin{array}{l}\text { weight and material of } \\
\text { components; } \\
\text { technical interactions } \\
\text { and processes } \\
\end{array}$ & $\begin{array}{l}\text { modest } \\
\text { (substantial improvements achieved by the } \\
\text { end of 1990s through gradual steps; but } \\
\text { improvements still possible) }\end{array}$ \\
\hline 4. poor ability to & \multicolumn{2}{|c|}{ nominal wind speeds for rated power $<5 \mathrm{~m} / \mathrm{s}$} & substantial \\
\hline $\begin{array}{l}\text { harness average } \& \\
\text { low wind speeds }\end{array}$ & \multicolumn{2}{|c|}{ nominal wind speeds for rated power $5-8 \mathrm{~m} / \mathrm{s}$} & modest \\
\hline
\end{tabular}

Data were collected from the following sources: the websites and printed publications of the Spanish Institute for Energy Saving and Diversification (IDAE), face-to-face interviews with main manufacturers and investment companies in Spain, as well as information published at companies' 
websites and in annual reports; market analysis articles published in professional journals such as Las Energias Renovables, Energia, and Windpower Monthly.

\section{Empirical Analysis of Wind Power Innovations in Spain}

This section discusses first the type and prioritization of innovation needs in Spain, from the perspective of maximizing the long term diffusion potential of wind power, given the country's wind resource characteristics. This is followed by a discussion of the innovations adopted between 1991 and 2000. The Spanish government actively stimulated the adoption of wind technology since 1980, when it adopted an ambitious policy to reduce the country's dependence on imported fossil fuels. This section differentiates between two diffusion periods: 1991-1994 and 1995-2000. The analysis starts with 1991, because this is when diffusion actually started with commercial projects; during the 1980s, projects had chiefly a research and demonstration purpose. In 1994, a new Royal Decree was adopted reducing the investment risks for wind power generators, which increased the interest of many types of developers in wind power [17].

\subsection{Innovation Needs and Priorities Given the Wind Resource Potential in Spain}

In Spain, the wind power potential is not very high, compared to other European countries. While wind resources are widely spread, most onshore regions have low wind speeds, below $5 \mathrm{~m} / \mathrm{s}$. The areas with high speed winds were exploited first, and there is intense competition-already since mid 1990s - for the sites with wind speeds that allow profitable projects under the applicable price support policy instruments. In 1998, the national renewable energy agency IDAE estimated that the wind power potential of Spain that could be exploited at production costs of up to $9 € \mathrm{c} / \mathrm{kWh}$ was 15,100 MW [29]. The estimate was based on wind technology designs that reach rated power only at nominal wind speeds for $11-16 \mathrm{~m} / \mathrm{s}$ (state-of-the-art at that time). By 2000 the price support for wind power was just slightly above $7 € \mathrm{c} / \mathrm{kWh}$, with a decreasing tendency [17], which can be confirmed now by 2009. Therefore, although the net technically exploitable potential is higher than the economically feasible potential for a price support of $9 € \mathrm{c} / \mathrm{kWh}$, for the purpose of this analysis one would be more realistic working with the latter. Although not inconceivable, it would be politically very difficult to give wind power a price support (much) above $9 € \mathrm{c} / \mathrm{kWh}$, as long as fossil-fuel based electricity technologies in Spain have production costs of up to $4.2 € \mathrm{c} / \mathrm{kWh}$ [17].

Technical experts consider that the ceiling for the integration of wind power in the national electricity system of Spain can be maximum 30\% of the total installed capacity in 1997 [28]. This is equivalent to around 33,600 MW wind power. By 2002, regional governments already had investment plans and spatial planning legislation allowing for the commissioning of 30,025 MW. These data show that by 2000 (and before), the situation in Spain from the perspective of long-term sustained diffusion of wind power could be described by Situation A in Figure 2. The technically feasible grid integration ceiling was higher (more than double: 33,600 MW/15,100 MW) than the wind power potential (exploitable at production costs up to $9 € \mathrm{c} / \mathrm{kWh}$ ). The contribution of grid-connected wind power to the national electricity system can only be expanded beyond the $15,100 \mathrm{MW}$ level if: 
(1) governmental price support increases without innovations in wind technology designs; and/or if

(2) innovations are adopted that bring about:

- the ability to operate at rated capacity in average and low wind speeds, below $8 \mathrm{~m} / \mathrm{s}$;

- improvements in turbine efficiency $\left(\mathrm{kWh} / \mathrm{m}^{2}\right)$;

- cost performance improvements.

Taking a long-term perspective and assuming that such innovations have been adopted and the limit of 33,600 MW grid-connected wind power has been reached, different innovations would be most useful. When the adopted innovations reverse the balance, and the (economically and technically) exploitable wind energy potential becomes higher than the grid integration potential (as in Situation B of Figure 2), grid-friendly technological designs can further lift the ceiling of wind power' contribution to the national grid system. But for the first stages of diffusion (perhaps decades, depending on the governmental price support) grid-friendly technological designs need not be the highest priority for the market adoption of wind power in grid-connected power plants. In terms of governmental and business innovation policies the above three types of innovations mentioned at point (2) should constitute a high R\&D priority, while grid-friendly technological designs should be given secondary priority.

The contribution of stand-alone wind power systems to the national electricity system can only be substantially increased if grid-friendly technological designs are developed and adopted by users, as first priority. Small electricity systems have much higher demands on grid stability, which makes this technological performance aspect much more important than others. Also a high priority for the diffusion of stand-alone applications in a resource-poor country such as Spain is the development and adoption of designs with the ability to operate at rated capacity in average and low wind speeds, below $8 \mathrm{~m} / \mathrm{s}$.

Isolated consumption areas (residential or commercial) typically incur high infrastructural costs to connect to the national electricity grid, resulting in high electricity bills. This means that the performance aspects with direct consequences for the production costs of wind power have a lower priority for such consumers, as long as the resulting electricity bills are still below those for the competing grid connection options. Consequently, the performance aspects of wind power investment costs and efficiency of wind resource harnessing $\left(\mathrm{kWh} / \mathrm{m}^{2}\right)$ need to be seen as secondary innovation and adoption objectives for stand-alone applications of wind power. Table 2 summarizes the considerations in this section regarding types of wind technology designs and innovation priorities for short/medium term, and for long term in Spain.

Table 2. Types of wind power plants and innovation priorities in different time perspectives.

\begin{tabular}{lll}
\hline Innovation needs & Short-medium term & Long-term \\
\hline Grid-connected & - improvements in turbine efficiency & - grid friendly designs \\
wind systems & $\left(\mathrm{kWh} / \mathrm{m}^{2}\right)$ & - ability to operate at rated capacity in \\
& - ability to operate at rated capacity in & wind speeds below $5 \mathrm{~m} / \mathrm{s}$ \\
& wind speeds below $8 \mathrm{~m} / \mathrm{s}$ & \\
& - cost performance improvements & \\
\hline Stand-alone wind & - grid friendly designs & - improvements in turbine efficiency \\
systems & - ability to operate at rated capacity in & $\left(\mathrm{kWh} / \mathrm{m}^{2}\right)$ \\
& wind speeds below $8 \mathrm{~m} / \mathrm{s}$ & - cost performance improvements; \\
\hline
\end{tabular}


Table 3 shows by how much the installed capacity of wind power increased during the two periods distinguished. It can be seen that the reduction in the investment risks associated with the 1994 Royal Decree for governmental price support lifted the investment interest considerably, although more factors contributed to this [17].

Table 3. Installed capacity of wind power put into operation in Spain [17].

\begin{tabular}{lcc}
\hline Year & $1991-1994$ & $1995-2000$ \\
\hline MW installed & $66 \mathrm{MW}$ & $2,823 \mathrm{MW}$ \\
\hline
\end{tabular}

\subsection{Innovations Adopted between 1991 and 1994}

34 wind projects were put into operation during these years, totaling $66 \mathrm{MW}$ [17]. Wind technology was supplied by seven manufacturers (five of which were Spanish) who upgraded the installed capacity per turbine from $55 \mathrm{~kW}$ to $500 \mathrm{~kW}$. More importantly, the four aspects of technological performance summarized at the end of Section 4 evolved as follows.

Short-medium term innovation needs for grid connected systems:

- The average technology-specific costs lowered from $960 € / \mathrm{kW}$ in 1990 to $780 € / \mathrm{kW}$ in 1994 , which can be viewed as a substantial improvement in the cost-performance aspect, as it represents an $18 \%$ reduction in only four years [30].

- For less than $30 \%$ of the installed capacity, developers used turbine designs with modest performance improvements from the standpoint of efficiency in wind energy harnessing (incorporating innovations of variable rotor speed and pitch control).

- None of the adopted designs was able to harness wind energy at average/low wind speeds.

Long term innovation needs for grid connected systems:

- For $28.5 \%$ of the $66 \mathrm{MW}$ capacity, developers used innovative technology designs with modest performance improvements in terms of grid-friendliness, as showed in Table 4 (designs that still had asynchronous generators). Only $1.5 \%$ of installed capacity was based on designs with synchronous generators, characterized by substantial improvements in grid friendliness. This was represented by two turbines imported from the German manufacturer Enercon and used in stand-alone applications - the only stand-alone project in these years.

Comparing these empirical findings with the short-medium term innovations needs for grid-connected systems in Spain (mapped in the second column of Table 2), it appears that developers invested overwhelmingly in technological designs that did not incorporate impressive innovations from the standpoint of diffusion expansion potential. The installed capacity per turbine increased tenfold, from $55 \mathrm{~kW}$ to $500 \mathrm{~kW}$, which is mostly responsible for the improvement in cost performances (an average reduction of $180 € / \mathrm{kW}$ ). However, one should not be misled by installed capacity increases, since the efficiency improvements in wind energy harnessing have been modest; these improvements have only been incorporated in less than a third of the total capacity installed during these years. Besides, none of the 'bigger turbines' was able to operate at nominal capacity in areas 
with average wind speeds below even $11 \mathrm{~m} / \mathrm{s}$ - let alone lower-wind-speed sites, which should be seen as a high priority for innovations in short-medium term.

Table 4. Technology designs adopted in Spain up to 1994, relevant from the perspectives of grid-friendliness and efficiency performances [17].

\begin{tabular}{|c|c|c|c|c|}
\hline \multirow{2}{*}{$\begin{array}{c}\text { Manufacturers } \\
\text { entering market } \\
\text { 1991-1994 } \\
\end{array}$} & \multicolumn{4}{|c|}{ Technical characteristics_-grid friendliness and efficiency perspectives } \\
\hline & Blade control & Rotor speed & Generator type & Technological design/market share \\
\hline Ecotecnia & \multirow{2}{*}{ Stall control } & \multirow{2}{*}{ Constant } & \multirow{6}{*}{ Asynchronous } & \multirow{2}{*}{ Conventional design $(70 \%)$} \\
\hline Made & & & & \\
\hline Desa & \multirow{5}{*}{ Pitch control } & Constant & & \multirow{4}{*}{$\begin{array}{l}\text { Modest improvements in grid } \\
\text { friendliness and efficiency }(28.5 \%)\end{array}$} \\
\hline Gamesa & & Variable (cmoll range) & & \\
\hline Acsa & & varradie (small range) & & \\
\hline AWP/ Kenneth & & & & \\
\hline Enercon & & Variable & Synchronous & $\begin{array}{l}\text { Substantial improvements in grid } \\
\text { friendliness and modest change in } \\
\text { efficiency }(1.5 \%)\end{array}$ \\
\hline
\end{tabular}

A possible explanation for these modest performance improvements of the adopted designs is that the governmental price support for wind power was still low, and exposed to higher political risks of support discontinuation. In order to compensate for poor and risky project economics, developers and financing agents chose for conventional wind technology designs, as they assumed lower technology-specific costs per $\mathrm{kW}$.

\subsection{Innovations Adopted between 1995 and 2000}

Hundreds of wind projects were put into operation during these years, totalling 2,823 MW. Just as in the previous period, the overwhelming wind power capacity was installed in the form of grid connected systems (at least 95\%). Wind technology was supplied by 15 manufacturers (five of which were Spanish) who upgraded the installed capacity per turbine from $500 \mathrm{~kW}$ to $1,650 \mathrm{~kW}$. The adoption of innovations considered as long-term needs for grid connected systems (right column of Table 2), was more impressive than the adoption of innovations useful for lifting the ceiling of wind power's contribution to the national grid in short/medium term. This means that - in the absence of a rational governmental planning of innovation objectives, characterizing Spain - the 'invisible hand' of the market has not guided manufacturers and investors towards the most diffusion-optimal designs.

The development of designs able to operate in average and low wind speeds has been viewed by the Spanish government only as 'Research Priority 3', throughout the 1990s and 2000s [29]. This is surprising for a country for which the wind energy potential is significantly below the grid integration capacity of $30 \%$. The framework proposed in this paper has identified designs able to operate in average and low wind speeds as a high short-term priority. When the location and size of wind power plants is well planned - that is, dispersedly located in sizes well manageable from a grid perspective, one needs not worry about grid friendliness too soon.

Use of average/low wind speed sites: By 2000, six manufacturers were concerned with 
technological designs for moderate wind speeds between 8 and $10 \mathrm{~m} / \mathrm{s}$. The Spanish Energia Hidraulica Navarra (EHN) was working in 2000 on a 1,300 kW prototype able to work at cut-in speeds of $2.3 \mathrm{~m} / \mathrm{s}$ and to reach rated power at $8 \mathrm{~m} / \mathrm{s}$. The industrial group MTorres with experience in aeronautics developed a 1,500 kW turbine for average wind speeds as well, of 8-10 m/s. Other designs for average wind speeds were developed by Ecotecnia $(750 \mathrm{~kW})$, Made $(850 \mathrm{~kW})$, and Gamesa $(850 \mathrm{~kW})$. All these five innovative designs were based on the long-established technological principle-horizontal axis turbine.

A new entrant on the Spanish manufacturing market introduced, however, a completely new technological principle, known as 'translation principle'. The Spanish company Enerlim presented in 2000 its $300 \mathrm{~kW}$ model for average wind speed of $8 \mathrm{~m} / \mathrm{s}$, to be further upgraded into $900 \mathrm{~kW}$ and 1,200 $\mathrm{kW}$ versions. However, no technology principle and design presented to the market during this period was yet able to reach rated power at nominal wind speeds of below $6 \mathrm{~m} / \mathrm{s}$. Hence, the above mentioned designs can be assessed as bringing modest improvements in wind technology's ability to harness energy from lower wind speed sites, viewed as a short-medium term priority for both grid connected systems and stand-alone systems. By 2000, the above models were mainly in demonstration phase, so one cannot yet talk about a 'market share' for these years.

In terms of the usefulness of the framework proposed in this paper, it is interesting to notice here that a focus on monitoring innovations based on the installed capacity would fail to recognize the importance of new designs such as those of Ecotecnia, Made and Gamesa just because they are 'below 1 MW designs' while 'the market moved on'. Using rotor diameter and hub height as technical indicators would definitely miss the innovation of Enerlim, which is based on panels in translation movement and does not even have a rotor and a hub.

Cost performances: The average technology-specific costs lowered from $780 € / \mathrm{kW}$ in 1994 , to $630 € / \mathrm{kW}$ by 2000 [30]. For this performance aspect, the progress was therefore smaller, compared to the previous period. These cost reductions were mainly achieved by means of economies of scale in production, rather than technical innovations in materials and technology. However, one needs to take into account that these are rough average levels: older conventional designs (often already cheaper) were produced in mass numbers and became even cheaper; the new designs (with modest and substantial performance improvements in the other three aspects differentiated in Section 4), assumed higher technology specific costs per $\mathrm{kW}$ installed.

Wind resource harnessing efficiency: this was considered a short-medium priority for grid connected systems in Spain. As showed in Table 5, for $72.2 \%$ of the installed capacity $(55 \%+17.2 \%)$, developers used technological designs that harness wind energy more efficiently in terms of $\mathrm{kWh} / \mathrm{m}^{2}$. The total market share of the three categories of technological designs does not add to $100 \%$ because $5 \%$ of capacity was represented by wind projects with technologies from other manufacturers than mentioned in this table or projects with mixed technologies.

As a result of this widespread adoption, the national average level of efficiency of all functioning turbines increased from $1000 \mathrm{kWh} / \mathrm{m}^{2}$ in 1996 , to $1,500 \mathrm{kWh} / \mathrm{m}^{2}$ or more in 2000 [23,31]. This increase is the result of (a) using designs with modest efficiency performance improvements and (b) good planning, by using designs with higher hub height at sites with adequate wind regimes for the nominal power of the respective technological designs. Consequently, the overall improvement in this performance aspect can be evaluated as substantial, at national level. 
Table 5. Technology designs adopted in Spain 1995-2000, from the perspectives of grid-friendliness and efficiency performances [17].

\begin{tabular}{|c|c|c|c|c|}
\hline \multirow{2}{*}{ Company } & \multicolumn{3}{|c|}{ Technical characteristics } & \multirow{2}{*}{$\begin{array}{l}\text { Market shares in } 2000 \text { per type } \\
\text { technological design }\end{array}$} \\
\hline & Blades control & Rotor speed & Generator type & \\
\hline Ecotecnia & \multirow{4}{*}{ Stall } & \multirow{4}{*}{ Constant } & \multirow{4}{*}{ Asynchronous } & \multirow{3}{*}{ conventional designs (22.8\%) } \\
\hline BonusBazan & & & & \\
\hline Made & & & & \\
\hline Nordtank & & & & preparing market entry in 2000 \\
\hline Made & \multirow{3}{*}{ Pitch } & Two-speeds & \multirow{6}{*}{ Asynchronous } & \multirow{6}{*}{$\begin{array}{l}\text { modest improvements in } \\
\text { grid-friendliness and efficiency } \\
(17.2 \%)\end{array}$} \\
\hline Acsa & & Variable & & \\
\hline Desa & & Constant & & \\
\hline Neg-Micon & Stall & Two speeds & & \\
\hline Gamesa & Pitch & Variable & & \\
\hline Kenneth & Pitch & Variable & & \\
\hline Nordex & Stall & Two speeds & \multirow{3}{*}{ Asynchronous } & \multirow{3}{*}{ preparing market entry in 2000} \\
\hline DeWind & Pitch & Variable & & \\
\hline Enerlim & Pitch & Variable & & \\
\hline $\begin{array}{l}\text { Gamesa } \\
\text { Eolica }\end{array}$ & \multirow[t]{2}{*}{ Pitch } & Variable & $\begin{array}{l}\text { Ingecon system } \\
\text { Synchronous }\end{array}$ & \multirow{2}{*}{$\begin{array}{l}\text { substantial improvements in } \\
\text { grid-friendliness and modest } \\
\text { improvements in efficiency }(55 \%)\end{array}$} \\
\hline Enercon & & Variable & Synchronous & \\
\hline EHN & \multirow{3}{*}{ Pitch } & \multirow{4}{*}{ Variable } & $\begin{array}{l}\text { Ingecon system } \\
\text { Synchronous }\end{array}$ & \multirow{4}{*}{ preparing market entry in 2000} \\
\hline MTorres & & & Synchronous & \\
\hline Made & & & Synchronous & \\
\hline $\begin{array}{l}\text { Enron (Zond } \\
\text { and Tacke) }\end{array}$ & Stall/Pitch & & $\begin{array}{l}\text { DVAR system } \\
\text { Synchronous }\end{array}$ & \\
\hline
\end{tabular}

Grid-friendly designs: short-medium term priority for stand-alone systems; long-term priority for grid-connected systems (see Table 2). Very few stand-alone systems were put into operation during these years. The most remarkable was that developed in 1999, as the first autonomous wind-park of Spain. The system was developed on the Canary Island of Las Palmas, through the cooperation of manufacturer Enercon, the Canary Technological Institute and an industrial company. The project consists of two Enercon turbines with synschronous generators of $240 \mathrm{~kW}$ each. The wind plant proved able to maintain constant the voltage and frequency of electricity, without need for additional load and for all wind speeds. In future, one may be able to witness an impressive increase in stand-alone wind power systems, because innovations in grid-friendly designs have been surprisingly widely adopted by grid-connected plant investors. This helped to bring down the technology-specific costs for these designs as well.

Some manufacturers - who are also very active as project developers in Spain, have rushed into the development and adoption of designs with synchronous generators. Although this is considered in Table 2 as a long-term priority for grid-connected system, looking at the macro-level of a national electricity system, in Spain, the un-balanced distribution of wind power investments has caused grid management problems. When wind systems are dispersedly attached to the national grid, in plant sizes 
that allow the grid to deal with the intermittency and fluctuations of supply, grid-friendly designs need not be a short-term priority.

In Spain, however, once a good and low risk governmental price support was in place, a frenzy of wind power investments was unleashed. A poorly designed administrative permitting system allowed the attachment of very large size wind systems to limited numbers of points in the grid, causing serious grid management problems. Anticipating that grid-friendly designs may be useful not only in long term, but also in short-term (to deal with the problems created by investment patterns), developers have started investing in, and adopting, grid friendly designs.

As showed in Table 5, for $17.5 \%$ of the capacity, developers used technology designs with modest performance improvements in terms of grid-friendliness (with pitch blade control and/or variable/two-speed rotors). The market share of designs with synchronous generators increased from $1.5 \%$ in 1995 to $55 \%$ by 2000 . As Table 5 shows, four more manufacturers were preparing market entry in 2000 based on designs characterized by substantial improvements in grid-friendliness. Innovations during these years included the Ingecon system of the Spanish Gamesa manufacturer (with EHN subsidiary) and the DVAR system of Enron, which have similar grid-friendly properties as synchronous generators. Many of these designs have 'below 1 MW' turbines and can easily be overlooked by the superficial market/policy analyst looking at size as an innovation indicator.

The surge in the development and adoption of grid-friendly designs can benefit soon for the diffusion of stand-alone systems, although that was not originally the objective of the innovative manufacturers. Stand-alone systems require however additional innovations to improve the reliability and storage capacity of the back-up components.

\section{Conclusion}

The analysis carried out in Section 7 illustrates the usefulness of the framework for the evaluation of on-shore wind technology innovations proposed in this paper. The framework suggests that it is more useful to take a diffusion perspective when analysing the innovative designs of wind technology developed and adopted in the market. 'Bigger' is not always beneficial. In the case of wind power, reporting innovations only in terms of installed capacity increase, hub height and rotor diameter is short-sighted.

In order to understand the diffusion expansion potential brought about by innovative designs, one needs to look at: How does the respective innovation help to reduce diffusion obstacles? How does the innovation help to lift the technical ceiling of wind power integration in the national electricity system? How does the innovation help to increase the wind energy resource potential that can be harnessed by wind technologies, making it possible to generate wind electricity also in the low-wind-speed areas? How does the innovation help to harness the wind energy resource potential more efficiently? And: how does the innovation help improve the cost performances of wind technology and give it a better fighting chance in the competition with conventional fossil fuel based technologies? Technical indicators for monitoring innovations are useful as long as they are able to suggest something in terms of whether the technology is capable to transform the energy potential of the resource it uses into 'realizable installed capacity', maximizing the theoretically achievable market share for that resource in national electricity systems. 
The case study illustrated that-based on the mainstream way of looking at technical innovations - one would not take special notice of most new designs (and the new technological principle) for wind power in Spain, characterized by performance improvements in the four selected diffusion perspectives, as they were mainly below $1000 \mathrm{~kW}$. The application of the evaluation framework proposed in this paper allows for a more realistic assessment of the contribution that new technological designs and principles can bring to the diffusion potential expansion of wind power.

In addition, the framework also enables a prioritization for innovation development and adoption that corresponds to the characteristics of the resource and of the national energy system in which it is used. The available wind energy potential may be lower or higher than the ceiling of wind power integration in the national electricity grid. This has consequences for the types of innovations that are most desirable, for different time horizons, in order to increase the technically/socially/economically feasible deployment of wind power. Likewise, the innovations most desirable in short-medium term may be different than those that would be most useful taking a long-term perspective. For policy-makers, it is important that they understand the country's innovation needs and priorities. Funding and human resources for research, development and demonstration are scarce. Innovation in all four performance aspects identified would be necessary, sooner or later. However, there are benefits in using scarce financial and human resources to address the diffusion obstacles and challenges that are likely to be faced sooner.

What is currently needed is not only a diffusion perspective in the analysis of innovations, but also an innovation perspective to be brought into diffusion analyses. The latter needs to be further integrated with perspectives looking at the resource potential context, the investors' behavior, the administrative and permitting context, the socio-economic context, as well as the political and price-support context. Planning and scenarios need to bring together expected developments in all these contexts. This would help underpin potential future diffusion obstacles that are caused by investment patterns or unforeseen developments in these other contexts. As the Spanish case study shows, the relationship between technical innovations and these 'surrounding context layers' is two-ways. Innovations may change investors' behavior. But investors' behavior may also have consequences for the technical innovations needed with priority: poorly planned investment patterns may actually give raise to (additional) diffusion obstacles, and reduce the grid-integration ceiling for wind power.

The approach proposed in this paper is to monitor innovations in wind power technology based on a set of diffusion-oriented performance aspects, and to integrate this systematically with diffusion analyses that look at all the other above-mentioned contextual factor. This would help substantially to bridge the current gap between the RET innovation literature and the technical studies, one the one hand, and the diffusion oriented literature of policy and market analysts, on the other.

The framework proposed in this paper is also useful for policy-makers in several ways. First, it makes the point that governmental strategies and funding allocation decisions for technological development and demonstration need to build upon reliable analyses of energy resource potentials. It is quite wasteful to invest public funds into RD\&D and technological analyses, when there is no clear idea about the quality and distribution of resources across the country. When a (even rough) mapping of available resources is available, this should be used when planning the governmental research 
objectives. Optimal diffusion is characterized by a good match between the technological designs used and the resource characteristics of the sites where investments can possibly be made.

The panic generated at several locations in Spain regarding the grid management impact of wind plants has transformed the development of grid-friendly designs into a 'Research Priority 2'. The 'Research Priority 1' of the government has remained, as in the past decades, the development of turbines with increased installed capacity. Turbines with higher capacity, e.g., above 1,500 kW, are typically needed for sites with high average wind speeds. As explained in Section 2, a turbine may have an impressive installed capacity, but it will be unable to reach that capacity during operation unless wind speeds are above certain high levels. In Spain the wind-rich sites (above $12 \mathrm{~m} / \mathrm{s}$ annual average) have been almost exhausted by 2008-2009. Investors have to accept sites with increasingly lower annual average wind speeds and lower availability (number of hours with 'good wind speeds' per year). This first governmental research objective may serve investment demands in foreign countries with good wind resources. But what Spain actually needs is the availability (at smaller costs) of technology designs of 'under $1 \mathrm{MW}$ ' capacity able to extract wind energy - and do so efficiently - at average and low wind speeds. However, the development of turbine for average speed sites is only considered as 'Research Priority 3' by the Spanish government.

Second, the framework makes clear the importance of long-term perspectives for RET innovation and diffusion strategies. Only a long-term perspective allows for an adequate prioritization of innovation objectives. Long-term perspectives provide also crucial input needed for climate change mitigation policies. Stabilizing the anthropogenic emissions of greenhouse gases at levels that prevent harmful climatic changes for societies and ecosystems, requires not $2 \%$, not $10 \%$ of renewable energy resources use; it requires a shift of entire national energy systems away from fossil fuels. No single renewable resource can replace fossil fuels; but there are many types of renewable resources that can complement each other. Policy-makers need to start thinking in terms of 'technically feasible levels of grid integration' for intermittent resources, and of 'maximum available potential' for all types of renewable resources. Modest, single digit market share objectives for RET contributions will not slow down climate change anymore. In this context, innovations in RET are still necessary, and a more realistic approach in mapping innovation priorities and assessing the new designs is an approach focused on their impact on lifting diffusion obstacles and expanding the diffusion potential.

\section{References}

1. Jacobsson, S.; Johnson, A. The diffusion of renewable energy technology: an analytical framework and key issues for research. Energ. Policy 2000, 28, 625-640.

2. Meijer, I.S.M.; Hekkert, M.P.; Koppenjan, J.F.M. The influence of perceived uncertainty on entrepreneurial action in emerging renewable energy technology; biomass gasification projects in The Netherlands. Energ. Policy 2007, 35, 5836-5854.

3. Toke, D. Explaining wind power planning outcomes: some findings from a study in England and Wales. Energ. Policy 2005, 33, 1527-1539.

4. Breukers, S. Institutional Capacity Building for Wind Power, a Geographical Comparison; Ph.D. Thesis; University of Amsterdam: Amsterdam, The Netherlands, 2007. 
5. Nadai, A. Planning, sitting and the local acceptance of wind power: some lessons from the French case. Energ. Policy 2007, 35, 2715-2726.

6. Wüstenhagen, R.; Wolsink, M.; Bürer, M.J. Social acceptance of renewable energy innovations: an introduction to the concept. Energ. Policy 2007, 35, 2683-2691.

7. Jacobsson, S.; Lauber, V. The politics and policy of energy system transformation-explaining the German diffusion of renewable energy technology. Energ. Policy 2006, 34, 256-276.

8. Walket, F.J.; Jenkins, N. Wind Energy Technology; Unesco Energy Engineering Series; John Wiley \& Sons: West Sussex, UK, 1997.

9. Kulsum, A. Biomass energy. In Renewable Energy Technologies-a Review of the Status and the Costs of Selected Technologies; World Bank Technical Paper No. 240, Energy Series; World Bank: Washington, DC, USA, 1994; pp. 32-39.

10. Fraenkel, P. Flowing too slowly_performance and potential of small hydropower. Renew. Energ. World 1999, 3, 20-28.

11. Hanse, A.D.; Iov, F.; Blaabjerg, F.; Hansen, L.H. Review of contemporary wind turbine concepts and their market penetration. Wind Eng. 2004, 28, 247-263.

12. Kamp, L.; Smits, R.; Andriesse, C. Notions on learning applied to wind turbine development in The Netherlands and Denmark. Energ. Policy 2004, 32, 1625-1637.

13. Godoe, H.; Nygaard, S. System failure, innovation policy and patents: fuel cells and related hydrogen technology in Norway 1990-2002. Energ. Policy 2006, 34, 1697-1708.

14. Dosi, G. Technological paradigms and technological trajectories. Res. Policy 1982, 2, 147-163.

15. Uyterlinde, M.A.; Junginger, M.; de Vries, H.J.; Faaij, A.P.C.; Turkenburg, W.C. Implicationsof technological learning on the prospectus for renewable energy technology in Europe. Energ. Policy 2007, 35, 4072-4087.

16. Neij, L. Use of experience curves to analyse the prospects for diffusion and adoption of renewable energy technology. Energ. Policy 1997, 23, 1099-1107.

17. Dinica, V. Sustained Diffusion of Renewable Energy-Politically Defined Investment Contexts for the Diffusion of Renewable Electricity Technologies in Spain, The Netherlands and United Kingdom; Twente University Press: Enschede, The Netherlands, 2003.

18. Renewable Energy Sources for Fuels and Electricity; Johansson, T.B., Kelly, H., Reddy, A.K.N., Williams, R., Eds.; Island Press: Washington, DC, USA, 1993.

19. Hislop, D. Energy Option-An Introduction to Small Scale Renewable Energy; Intermediate Technology Publications: London, UK, 2002.

20. Jones, J. Coming of the giants - are there limits to the size of wind turbines? Renew. Energ. World 1999, 1, 12-19.

21. Wind Energy: the Facts, Volume I-Technology; European Commission Directorate of Energy: Brussels, Belgium, 1997.

22. Garcia, R.; Calantone R. A critical look at technological typology and innovativeness terminology: a literature review. J. Prod. Innovat. Manage. 2002, 19, 110-132.

23. Avia Aranda, F. Estadio de desarrollo tecnologico del aprovechamiento de la energia eolica. Energia-Ingenieria Energetica y Medioambiental 2000, 1, 21-30.

24. Hartnell, G.; Landberg, L. Wind on the system - grid integration of wind power. Renew. Energ. World 2000, 3, 21-32. 
25. Fixed and variable speed concepts compared. Wind Power Monthly, 1 May 2000; Available online: http://www.windpowermonthly.com/news/login/958861 (accessed on 23 October 2000).

26. Lara, A. Energia Eolican en Espana. Las Energias Renovables 2000, 4, 16-18.

27. Variable speed variation. Wind Power Monthly, 1 February 1998.

28. Menendez, E. Las Energias Renovables-Un Enfoque Politico-Economico; Los Libros de la Catarata: Madrid, Spain, 1998.

29. Plan Para el Fomento de las Energias Renovables en España [Plan for the Stimulation of Renewable Energy in Spain]; Instituto de Divercificacion y Adhorro de Energia: Madrid, Spain, 1999.

30. Informe Annual; Instituto de Divercificacion y Adhorro de Energia: Madrid, Spain, 1999.

31. Spain—national activities. In Wind Research and Development; International Energy Agency: Vienna, Austria, 2000; pp. 149-158.

(C) 2010 by the authors; licensee Molecular Diversity Preservation International, Basel, Switzerland. This article is an open-access article distributed under the terms and conditions of the Creative Commons Attribution license (http://creativecommons.org/licenses/by/3.0/). 